التقنيات الحديثة لمعالجة الأسطح الخزفية

Modern techniques to treatment of ceramic surfaces

$$
\text { أ. أدا عمر عبد العزيز }
$$

الأستاذ المتفرغ بقسم الذزف و رئيس قسم الذزف الأسبق قسم الذزف ـ ـلية الفنون التطبيقية

Prof. Dr. Omar Abdel Aziz

Professor of Ceramics Department, Faculty of Applied Arts

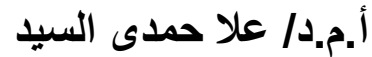

أستاذ مساعد دكتور قسم الخزف ـ كلية الفنون التطبيقية

Assist. Prof. Dr. Ola Hamdy El Said

Assistant Professor, Department of Ceramics, Faculty of Applied Arts

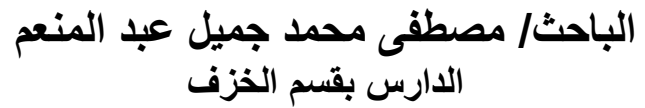

Researcher. Mostafa Mohamed Gamil Abdel Moneim

Studied in the Ceramics Department

drolahamdy90@gmail.com

mostafagamil2008@hotmail.com

يتناول هذا البحث تقنيات معالجة السطح الخزفى فى مراحل قبل الحريق ( البسكويت ) و بعض التقنيات الحديثة و

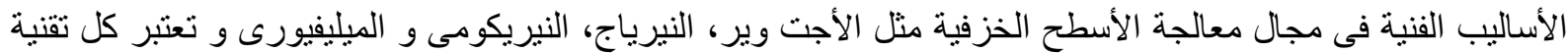
من هذه التقنيات نوع من أنواع التزخيم. تتميز معالجة السطح الخزفى بخصائص فنية و تقنتية واسعة و متداخلة و متتوعة تساعد على اثراء المنتج الخزفى جماليا. على الرغم من ذلك تقنقر المنتجات الخزفية المصرية هذة الخصائص و القيم الجمالية.

\title{
Research Abstract
}

This research deals with the techniques of ceramic surface treatment in the stages before firing (biscuits) and some modern and techniques and technical methods in the field of ceramic surface treatment. And the modern techniques such as Agateware, Neriage, Nerikomi and Millefiori and each of these techniques is a type of marbling.

The ceramic surface treatment features a wide range of technique and technical characteristics, overlapping and varied, which can help to enrich the ceramic product aesthetically. However, Egyptian ceramic products lack these characteristics and aesthetic values.

بتطلب إنتاج المنتجات الخزفية قدر كبير من الوقت و الجها و التفكير ـ لانها بتمر بالعديد من المراحل من مرحلة

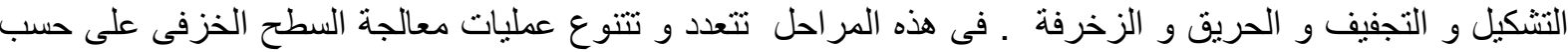

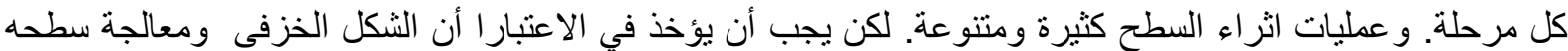

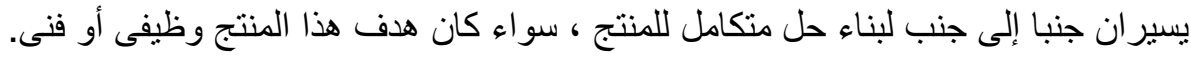

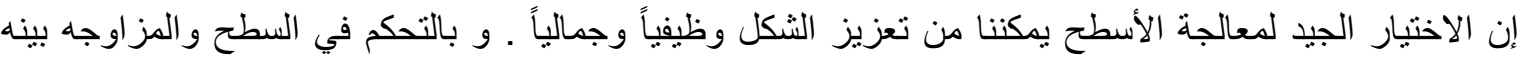

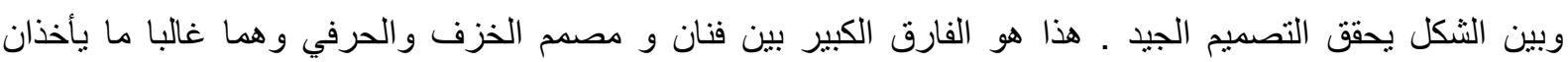


تتميز معالجة السطح الخزفى بخصائص فنية و تقنية واسعة و متداخلة و متنو عة تساعد على اثراء المنتج الخزفى جمالبا. على الرغم من ذلك تفتقر المنتجات الخزفية المصرية هذة الخصائص و والقيم الجمالية . بمكن تحديد المشكلة بهذا التساؤل: ـ ـ لماذا يوجد انفصال فى التفكير و فى التنفيذ بين عملية تصميم المنتج الخزفى و بين طرق معالجة سطحه على الرغم

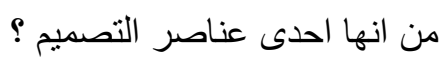
- يف يمكن لمصمم الخزف بخلفيته العلمية والفنية ان يحقق المز اوجة بين تصميم المنتج الخزفى و بين طرق معالجة

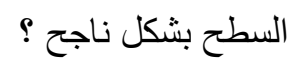
أهمية البحث: تبرز أهمية هذا البحث في: 1- الإستفادة من طرق معالجة الاسطح فى الإنتاج النصف كمى للوصول الى منتج خزفى ذو مو اصفات وظيفية وجمالية بجودة عالية. 2- توضيح أهم و أحدث التقنيات و الاساليب المستخدمة فى معالجة أسطح المنتجات الخزفية ثنائية الابعاد و ثلاثية الابعاد .

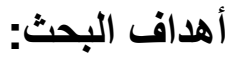
1- در اسة طرق وتقنيات معالجة الاسطح المختلفة و توظيفها بشكل جيد فى عملية تصميم المنتج. 2- الوصـول الـى تصـميم نـاجح مـن خـلال تقنيـات و طـرق معالجـة السـطح بحيـث تناسـب مـع طريقـة الإنتـاج النصف كمى. 1- يمكـن لمصـمم الخـزف ان يلعـب دورا هـام فـى الإرتقـاء بمسـتوى جـودة المنتجـات الخزفيـة و قيمتهــا الجماليـة و الاستخدامية و المشاركة بها فى الأسواق المحلية و العالمبة.

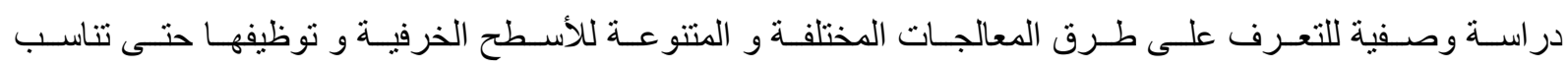
الإنتاج النصف كمى. 2- الإطار العملى: ( المنهج التجريبى ) سوف يقوم الباحث بالتطبيق العملي لمعالجات الأسطح الخزفيـة و نوظيف بعض التقنيات و الاسـاليبو الدمج بين البعض منها . 1- استخدام التقنيات اليدوية فى معالجة الأسطح الخزفية فى الجانب التطبيقى. 2- محاولة استخدام الطينات و الخامات المحلية فى جميع مر احل الإنتاج. 
يتطلب إنتاج المنتجات الخزفية قدر كبير من الوقت و الجهد و التفكير ـ لانها بتمر بالعديد من المراحل من مرحلة التشكيل

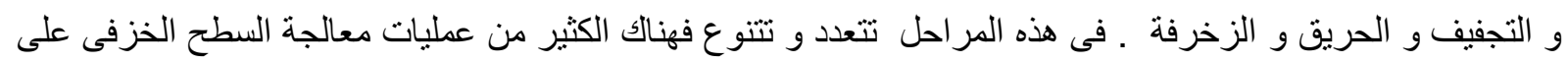

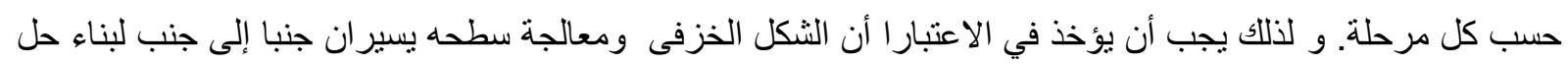

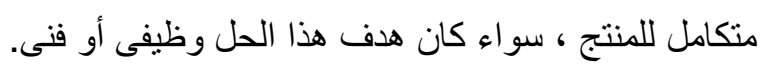
وتعرف معالجة الأسطح بأنها مجموعة العمليات والمهارات و النظريات التطبيقية أو المعرفية المرتبطة و اللازمة لإنتاج

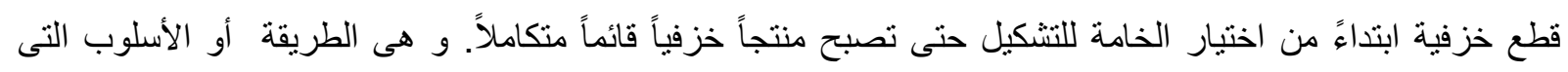

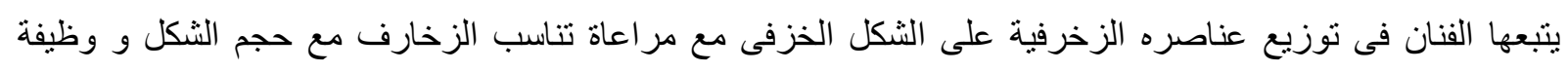

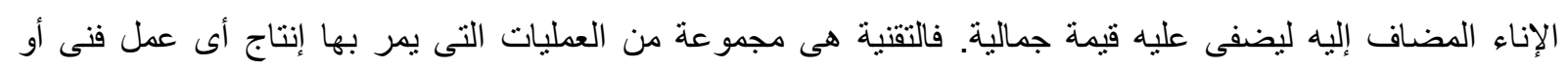
صناعى حتى يصبح منتجاً قائماً. فمعالجة الأسطح فى مجال الخزف مختلفة و متتوعة وذات إمكانيات كثثرة سواء كانت فى المرحلة الرطبة أو المرحلة الجافة أو مرحلة ما بعد الحريق الأول فكل مرحلة من هذه المراحل لها معالجات سطحية مختلفة تصلح لمرحلة دون

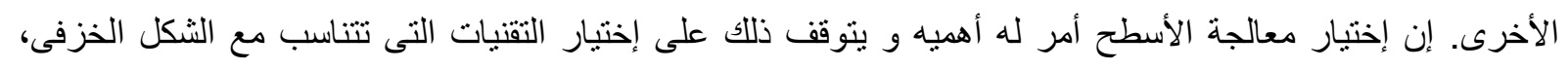

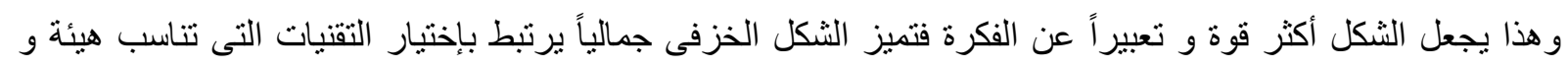
وظيفة الثكل.

وقد تختلف معالجة الأسطح سواء كان الثكل مسطحاً أو مجسماً، فكل شكل له اسلوبه الخاص فقد تصلح بعض المعالجات على الأشكال المسطحة و قد لا تصلح على الأشكال المجسمة ولابد أن يكون الهدف من اختبار هذه المعالجات لإبراز هدف معين لدى الخزاف و الفنان و إثراء الثكل سو اء كان يجب جمالياً أو تعبيرياً.

\section{معالجة الأسطح بالطريقة دمج الطينات الملونة

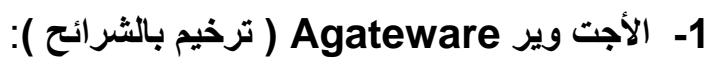

هو فخار مزخرف بمزيج تباين الطينات الملونة. كلمة أجت وير مشتقة من حجر العقيق التى هى عبارة عن طبقات

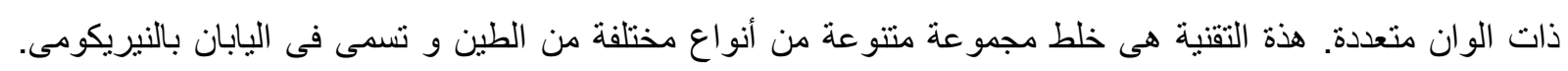

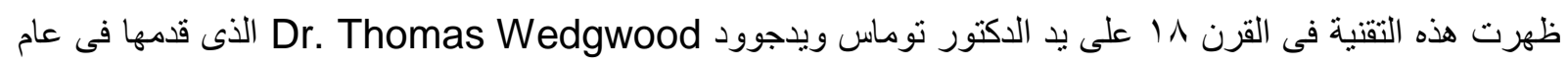
م. استخداموا الخز افين الطين الأبيض أو الفاتح جداً كقاعدة من أجل تجنب التشققات و كسر التى تحدث بسبب خلط مجموعة متنو عة من أنواع مختلفة من الطين. ثم يضيفون الألو ان في شكل صبغات أو أكاسيد. ينم إضافة الألوان إلى الطين عندما

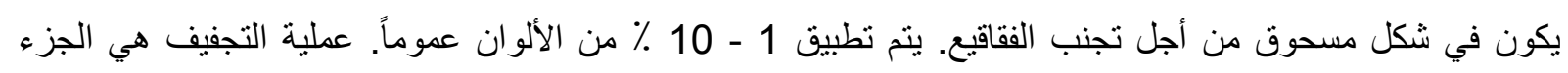

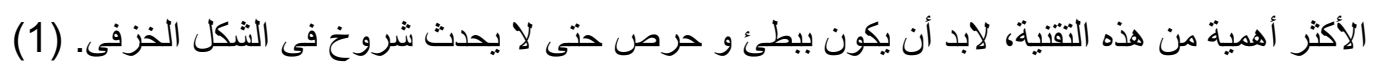

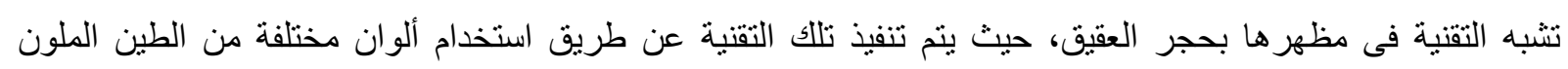

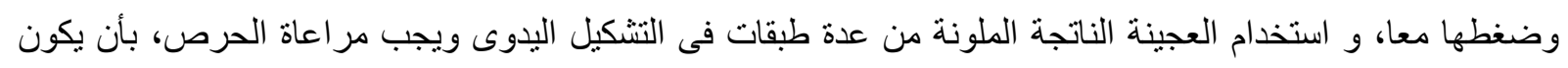

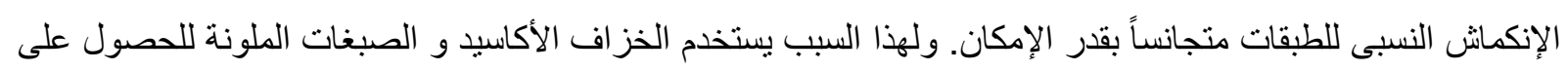

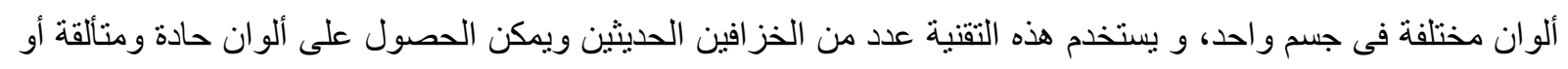
ألو ان مندمجة و هادئة. 
يتم فى الأجت وير مزج الثرائح، بأن تقطع شريحتان من الطين وتمزجان معاً عن طريق الضغط، و ينطبق هذا على

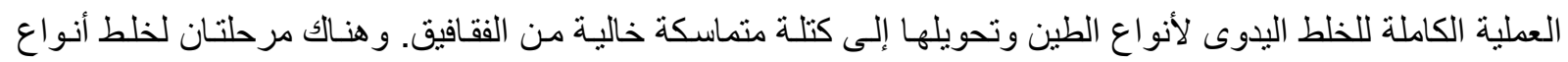

الطين المختلفة أو ذات درجات التماسك المختلفة، كما يمكن تنفيذ تلك التقنية من خلال طريقتين:- (2) أ) الخلط بواسطة الطبقات: يقطع الطين على صورة شرائح رقيقة ثم نوضع فوق بعضها بالتبادل، وفى حالة إضافة الجروج يمكن نشرة بين الطبقات. ومن المكن وضع طبقات مختلفة من الطين الناعم و الصلب ثم تقطع الكومة بأكملها بصورة رأسية، ورفع أحد النصفين و يوضع فوق النصف الآخر، مع توخى الحذر حتى تظل الطبقات أفقية، ثم تكرر العملية حتى تندمج الطبقات معاً، كما فى شكل ( 1 ( ). ب)تقطع كتلة الطين على شكل كرات ثم تعجن الكرات معاً عن طريق الضغط عليها من الامام ومن الداخل، أو بالطريقة الحلزونبة التى تؤدى إلى الحصول على كتل أكبر من الطين، كما فى شكل ( 2 ( ). (وقد تمكن بعض الخز افين من الحصول على نأثثر يمكن التحكم فيه بمعدل أكبر وذلك عن طريق وضع شريحة رقيقة من

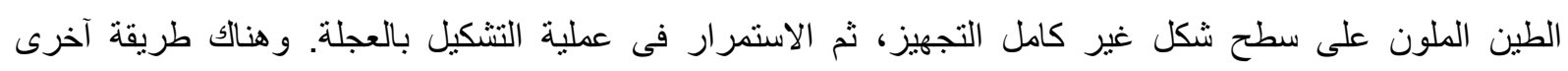

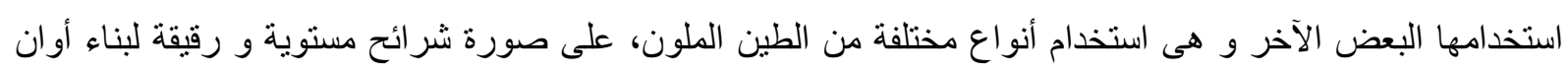

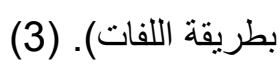

تعطى تللك التقنية قيمة جمالية تظهر من خلال العلاقات اللونية التى تحدث من الدمج و التقطيع، أو من خلال الوصول إلى شكل خزفى قائم بذاته من خلال تللك التقنية، و يرى الباحث أيضاً أن هذه الطريقة تسمح للخز اف بالتحكم فى التصميم أكثر من تقنية الترخيم العادية، يمكن الحصول على تصميمات غير منتظمة من خلال استخدام شرائح من الطينات الملونة

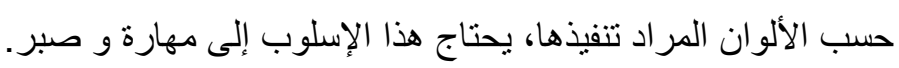

(1)https://www.britannica.com/art/agateware

(2) هبة محمد إبراهيم شحاتة "تقنيات معالجة السطح الخزفى لإثراء الأثكال الخزفية" رسالة ماجستير، كلية التربية الفنية - قسم التعبير المجسم،

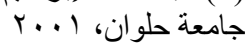
(3) هبة محمد إبر اهيم شحاتة "تقتيات معالجة السطح الخزفى لإثراء الأثكال الخزفية" رسالة ماجستير، كلية التربية الفنية ـ قسم التعبير المجسم،

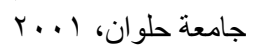




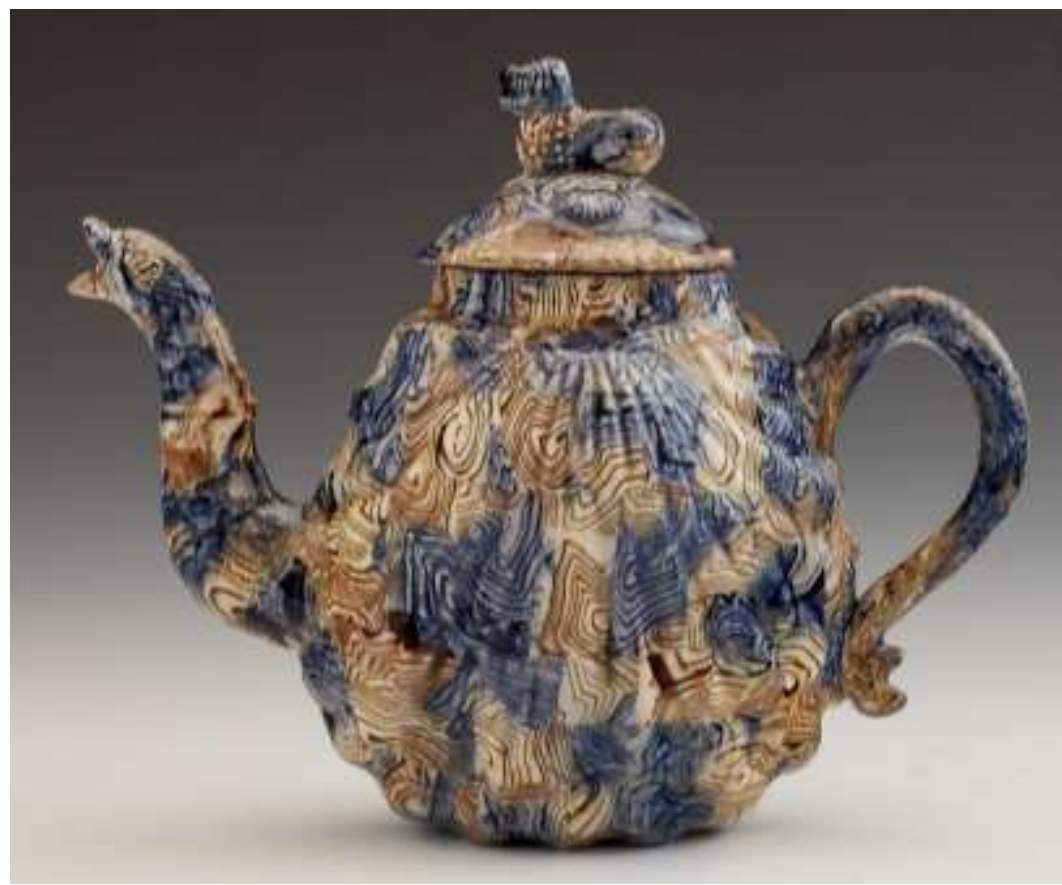

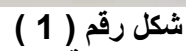

الخلط بواسطة الطبقات

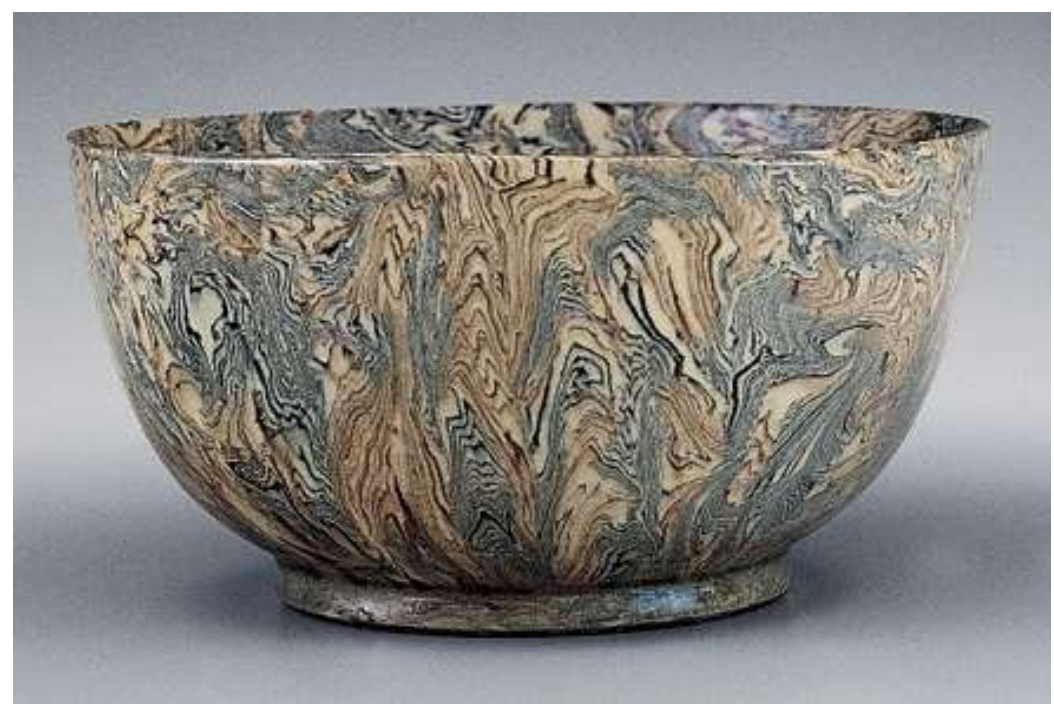

شكل رقم ( 2 ( ) ملطنة

النيرياج Neriage ( نوع من أنوع التطعيم ):

تستخدم تقنية النيرياج فى تشكيل الاعمال الخزفية بكثرة عند الخزافين الفرنسيين و العالميين. و يعنى مصطلح

بالعصر الرسوبى أو الطبقات الرسوبية فى بعض الجبال حيث تتكون معظمها من طبقات مختلفة الألوان احدثتها عوامل التعرية على مر السنين. وقد استفاد الخزافون من ذلك بإحداث مظاهر تشكيلية شبيهه باستخدام طبقات الطين المتعدد الألوان، إلا إنهم انطلقوا فى الإبداع من خلالها عن طريق أخذ المقاطع الرأسية و الأفقية المائلة لإحداث تصميمات تتصف بالطابع الهندسى.

(1)https://www.pinterest.com/pin/290130400976880900/?lp=true

(2)http://www.chipstone.org/article.php/78/Ceramics-in-America-2003/Swirls-and-Whirls:-English-AgatewareTechnology 
النيرياتج من معالجات السطح المستخدمة فى اليابان فى القرن 1/، حيث ينم وضع شرائح من الطين ذات الألوان المتناقضة فوق بعضها وتقطع و تلف و تتحول إلى كتلة ثم تقطع إلى شرائح، وتستخدم فى تصميمات حلزونية أو تصميمات آخرى ذات ألوان مرقمة وتضغط القطع إلى جوار بعضها فة قالب وذلك حتى تتكون طبقة واحدة ممتدة. و قد شاع إستخدام طريقة النيرياج فى الغرب وذللك لما تتصف به من تأثير ات جماليه بالغة. وتعتبر تقنية النيرياج التى يتم فيها دمج شرائح ملونة من الطين من التقنيات الهامة التى تم إحيائها فى السنوات القليلة

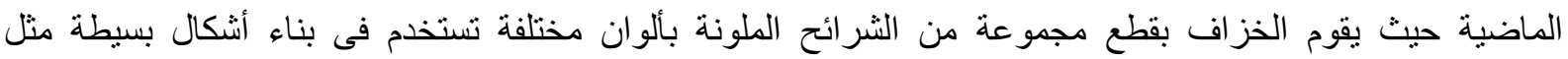
السلاطين. ويتطلب استخدام هذه التقنية ضرورة استخدام قالب من الجبس، وذلك لسند الأشكال التى تبنى بداخله من خلال استخدام شر ائح مفرودة من الطين يتم لصق حو افها معاً، وذلك عن طريق استخدام كمية قليلة من الماء أو الطين السائل. ومن المكن التحكم فى الألوان و النماذج بدقة كبيرة لا توجد خلال استخدام الطرق الآخرى. وهناك ميزة إضافية باستخدام أجسام البورسلين وهى كونها شبه شفافة، ويؤدى ذلك إلى إمكانية مرور الضوء بداخلها واختلاطه مع مختلف الألوان المستخدمة فى الأسطح الداخلية والخارجية، بل إنه فى حالة إستخدام الأجسام الطينية التى تتصف بصفة الإعتام فأن صفات النموذج تنعكس على الثنكل من الجانبين الداخلى والخارجى لجدارن الإناء الذى ينم بناؤه من شر ائح الطين الملون.

و هذه التقنية يستخدم فيها الطين الفاتح والداكن الذى يقطع على هيئة شرائح ثم كتل صغيرة يعاد نرتيبها للحصول على شر ائح ذات نماذج هندسية ملونة، وذلك عند الدمج بينها بعناية فى قالب مقعر لتكوين نموذج منطابق فى السطحين الداخلى هنى و الخارجى للإناء.

ويمكن الحصول بواسطة تقنية النيرياج على نماذج هندسية غاية فى الدقة و ذلك من خلال خطة مدروسة و و واعية من قبل فيل

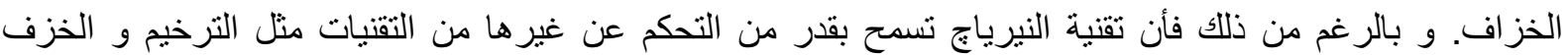

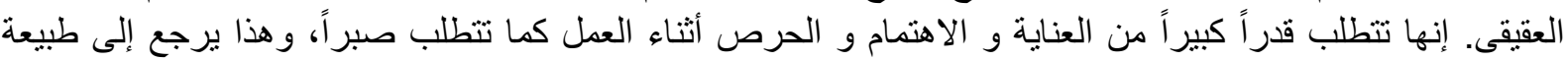

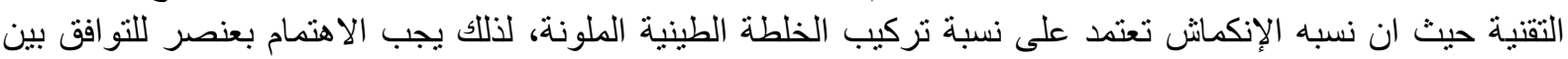

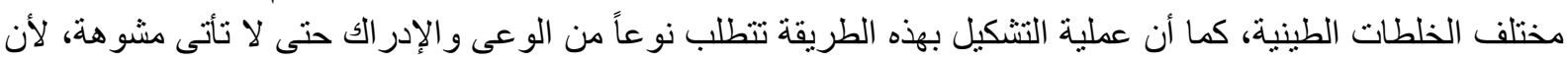

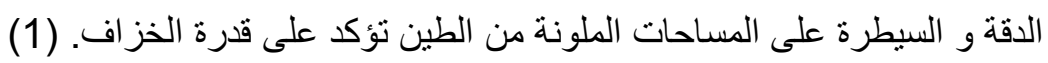

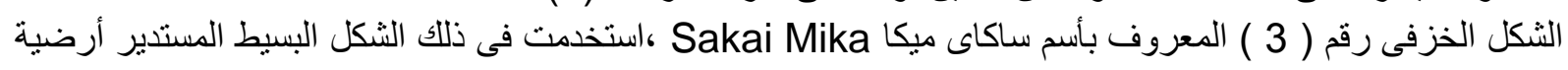
ناجحة لعناصرها و أشكالها الملونة الموزعة بشكل حيوى، حيث تحتوى على كل عنصر الحركة الذى قامت بتجسيده بنجاح فقد استغلت تقنية التشكيل من خلال القالب لإظهار جماليات الطين المدمج. قامت كذللك بإظهار الحس التلقائى البسبط مـن خـال العناصـر الهندسية البسيطة وآيضـاً مـن خـلال المجموعـة اللونيـة المستخدمة فى علاج السطح حيث لم يعالج السطح من خلال الطلاءات.

و يمكن الحصول على تأثثر لونى معقد بواسطة تقطيع طبقات من الطينة متعددة الألوان على شكل شئ شر ائح أو أجزاء

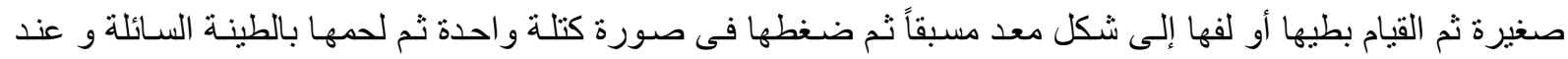

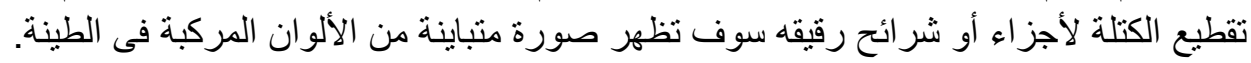

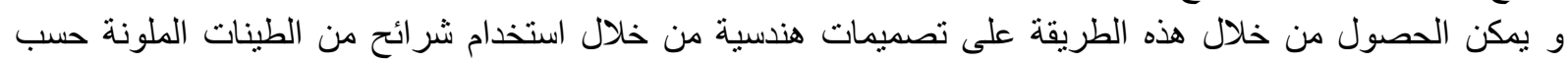
التصميم الهندسى المر اد تتفيذه و يمكن أيضاً الإستعانه بقوالب لضغط الطينات الملونة حسب التصميم المطلوب و نرتب

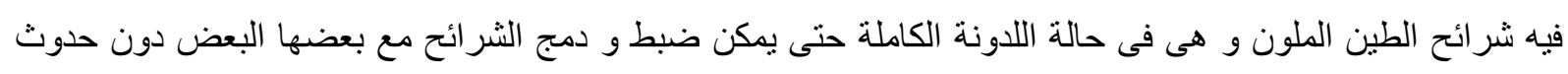
التشقق أو الإنفصال بين الأجز اء أو الثرائح.

(1) هبة محمد إبر اهيم شحاتة "تقنيات معالجة السطح الخزفى لإثر اء الأشكال الخزفية" رسالة ماجستير، كلية التربية الفنية ـ قسم التعبير المجسم،

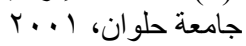


و هذه الطريقة تسمح للخزاف بالتحكم فى التصميم أكثر من تقنية الترخيم، و يحتاج هذا الإسلوب إلى عناية خاصة و صبر شديد، لتجنب مشكلات انفصال الأجزاء و حدوث التشققات أثناء مرحلة التجفيف، فلابد أن تتم هذه المرحلة ببطئ فلا يخلو الأمر من المشكلات حيث يمكن أن تؤدى الأكاسيد و صبغات إلى حدوث انكماش غير متجانس بين الأجزاء مما يؤدى إلى نثوه أماكن الاتصال بين أجز اء الثكل و يمكن التغلب على ذلك من خلال: أ. اختبار نسبة المادة الملونة بعناية، و التى تضاف على تركيبة الطينة الأساسية للتأكد من عملية التو افق بينهما. ب. إتمام عملية الحريق ببطئ شديد إلى نهاية الدرجة المطلوبة. ج. بعض التصميمات أو الأشكال تحتاج إلى دعائم ( مساند ) أثناء عملية الحريق لتساعد الأشكال على الاحتفاظ بشكلها.

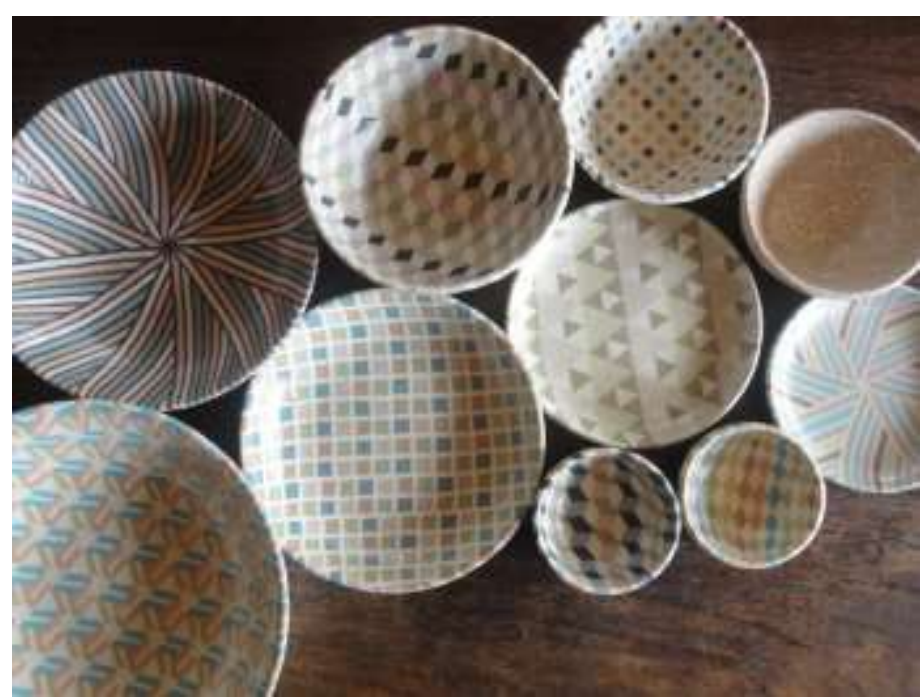

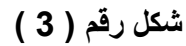

طبق ذات أشكال ملونة موزعة بشكل هندسى يوضح الخداع البصرى

النيريكومى Nerikomi ( التشكيل بالترخيم المنتظم ):

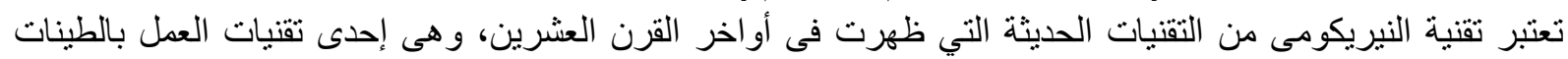
المدمجة. وتتميز تقنيات الطين المدمج بأن الوحدات الطينية ذات الألوان المتعددة تساعد على إمكانية الحصول على نظم زخرفية متعددة ومتنو عة سواء عند التشكيل على الدو لاب أو بالطرق اليدوية أو بالتشكيل فى قالب و الذى لابد من التأكد عليه فى هذا المجال هو تو افر عنصر التجانس بين تلك الخلطات الطينية المختلفة حيث يجب أن تكون نسبة الإنكماش واحدة بين مختلف الخلطات كذلك نسبة اللدونة و القابلية للتشكيل واحدة حتى تصبح جميعها وحدة تشكيلية متماسكة بالرغم من تعدد ألو انها وخواصها التركيبية التى تضمن الخواص الطبيعية و الكيميائية.

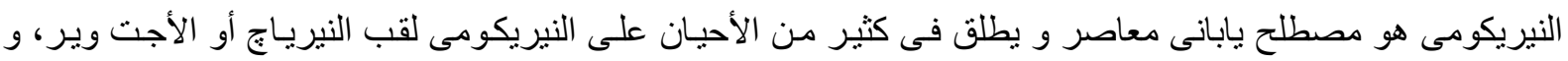

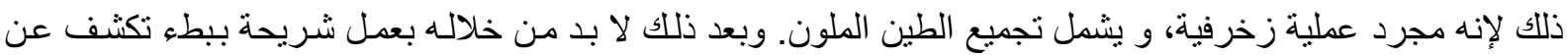
نمط الزخرفة. (4) (4)

(1)http://www.dailyartmuse.com/2007/01/02/neriage-nerikomi/

(2) و ائل فاروق إبر اهيم "در اسة تجربية لمعالجة سطح الإناء الخرفى من خلال تقنية النيرياج" رسالة ماجستير، كلية التربية الفنية، جامعـة حلوان،

(3)https://www.pinterest.co.uk/pin/557883472586393802/?lp=true 
ورغم تعدد طرق التشكيل وتقنياتة إلا أن الأساس فى التشكيل بالطينات المدمجة يظل واحد حيث يعتمد على أن قطعة الطين بلون ما تدمج و تلاصق قطعة طينية من لون آخر مخالف. ومن أبرز ما يميز طرق التشكيل بالطينات المدمجة أن التشكيلات والإبداعات الموجودة على سطح الثكل الخزفى ليس رسوما ظاهرية ملونة بالفرشاة أو بأى طريقة من طرق التلوين المعروفه و لكنها رسوم متداخلة فى صميم الجسم نفسه.

فأذا أجرينا مقطعاً فى إناء أو شكل خزفى مشكل بطريقة الطين المدمج سنجد هذا اللون أو التصميم نافذين إلى الوجه المقابل للجسم أي أن الخلط الملون ليس رسماً على واجهته الخارجية فحسب بل هو من ذات الطينة الطينة الخزفية. وقد اعتمدت تقنية النيريكومى على الطينات الملونة ذات التجانس فى معدل الانكماش كخامة أساسية للتشكيل وكذلك هن مرونة الطين التى تساعد على التشكيل وتحقيق الافكار. و تعتمد هذه الطريقة على استخدام ما لا يقل عن أربع أنواع من الطين المختلفة الألوان مع إضافة نسب من مسحوق الطين المحروق " الجروج Grog " حيث يؤدى ذلك إلى خفض معدل الإنكماش حتى لا تتفلق وتتفصل الألوان المختلفة من الطينات الملونة ويتم تشكيل شر ائح ذات الألوان المختلفة من بن الطين و غيرها من الكتل المستطيلة بعاد نرتيبها فوق بعضها البعض للحصول على نموذج ذى صفة هندسية وطريقة

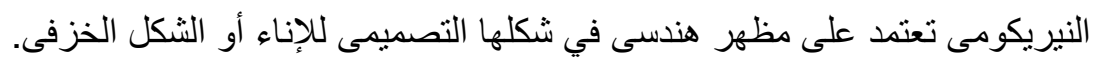

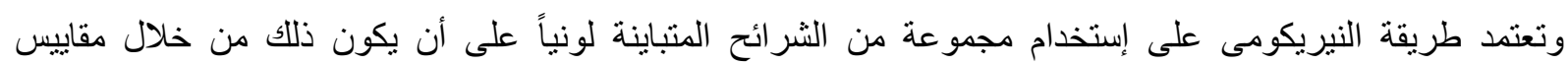
للحصول على سمك محدد للثر ائح التى تم تقطيعها بمسافات معلومة إلى شر ائح طويلة ثم إعادة ترتيب هذه الثر ائح عن طريق التبادل والتوافق بحيث يكون فى النهاية شريحة بيضاء مثلا ملاصقة لثريحة سوداء وتتم عملية الدمج بخش الحواف الجانبية للشر ائح و وضع محلول الطين ثم تجميعها ودمجها معاً بعناية و لابد أن تحدث هذه الطريقة و الطينات فى حالة اللدانة لكى تدمج وتتحد دون حدوث تشققات أثناء الجفاف و التسوية. كما انه يمكن الحصول على نماذج هندسية غاية فى الدقة و التعقيد باتباع تقنية النيريكومى من خلال تقطيع شر ائح الطينات

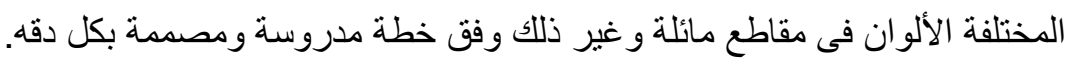
ومن أهم العمليات التى يجب أن تر اعى فى الأشكال التى تم تنفيذها بطريقة أو تقنية النيريكومى هي مرئه مرحلة التجفيف حيث يجب على الفنان أن يكون حريصاً جداً و دقيق فى هذه المرحلة حيث أن التجفيف المباشر والسريع يؤدى إلى انفصال

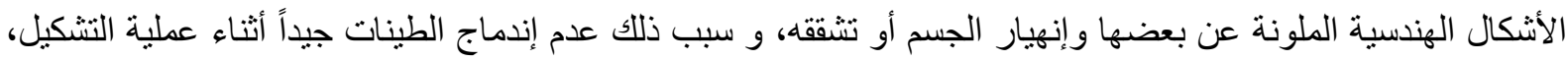
بأضافة إلى عدم التطابق الكامل فى لدانة الطينات النى تؤدى إلى الأختلاف فى إنكماش الطينات و تشققها. (1) 

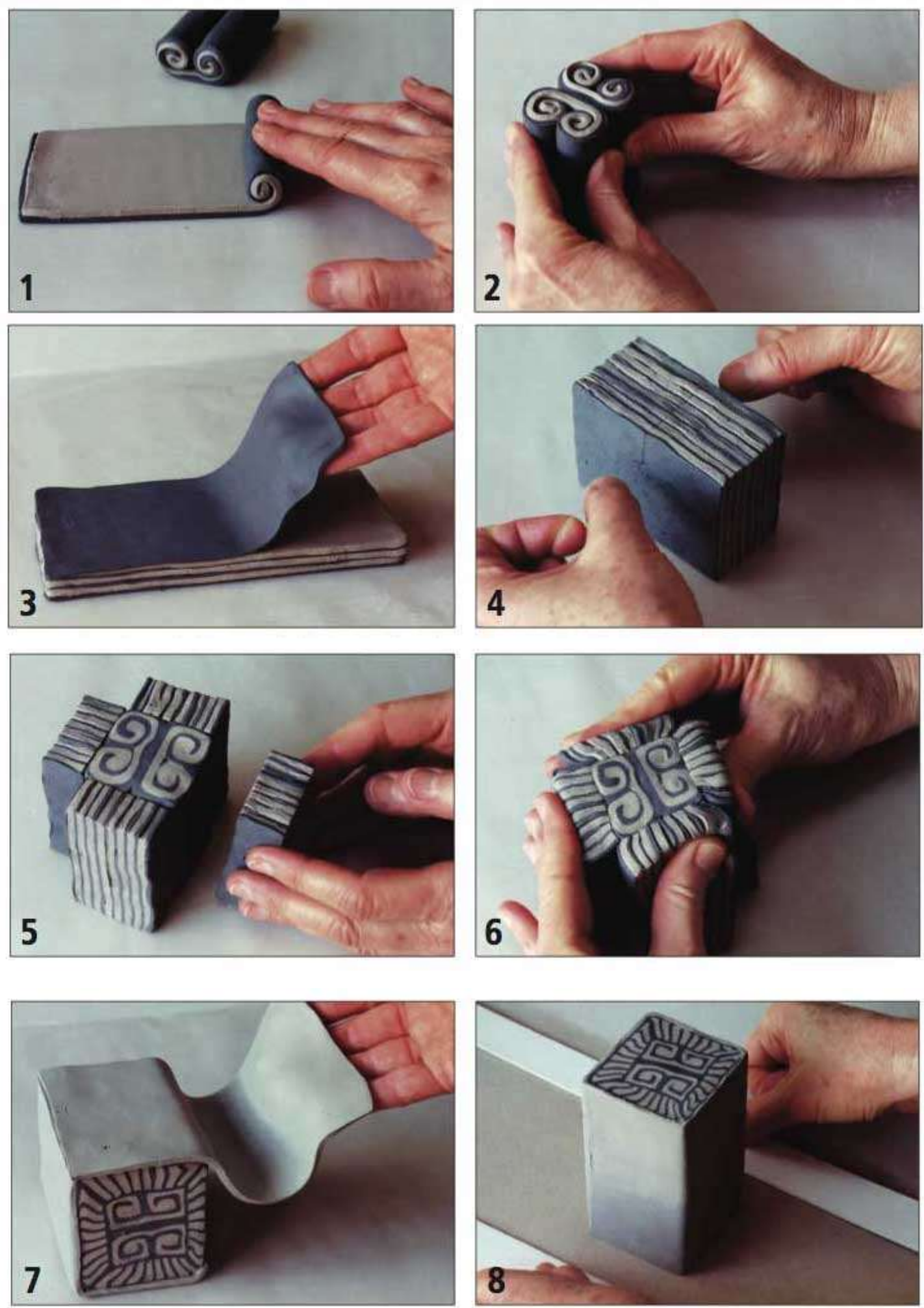

(1)http://ceramicartsdaily.org/ceramic-supplies/ceramic-colorants-ceramic-supplies-2/creating-neriage-blocksdecorating-with-colored-clay-patterns/ 

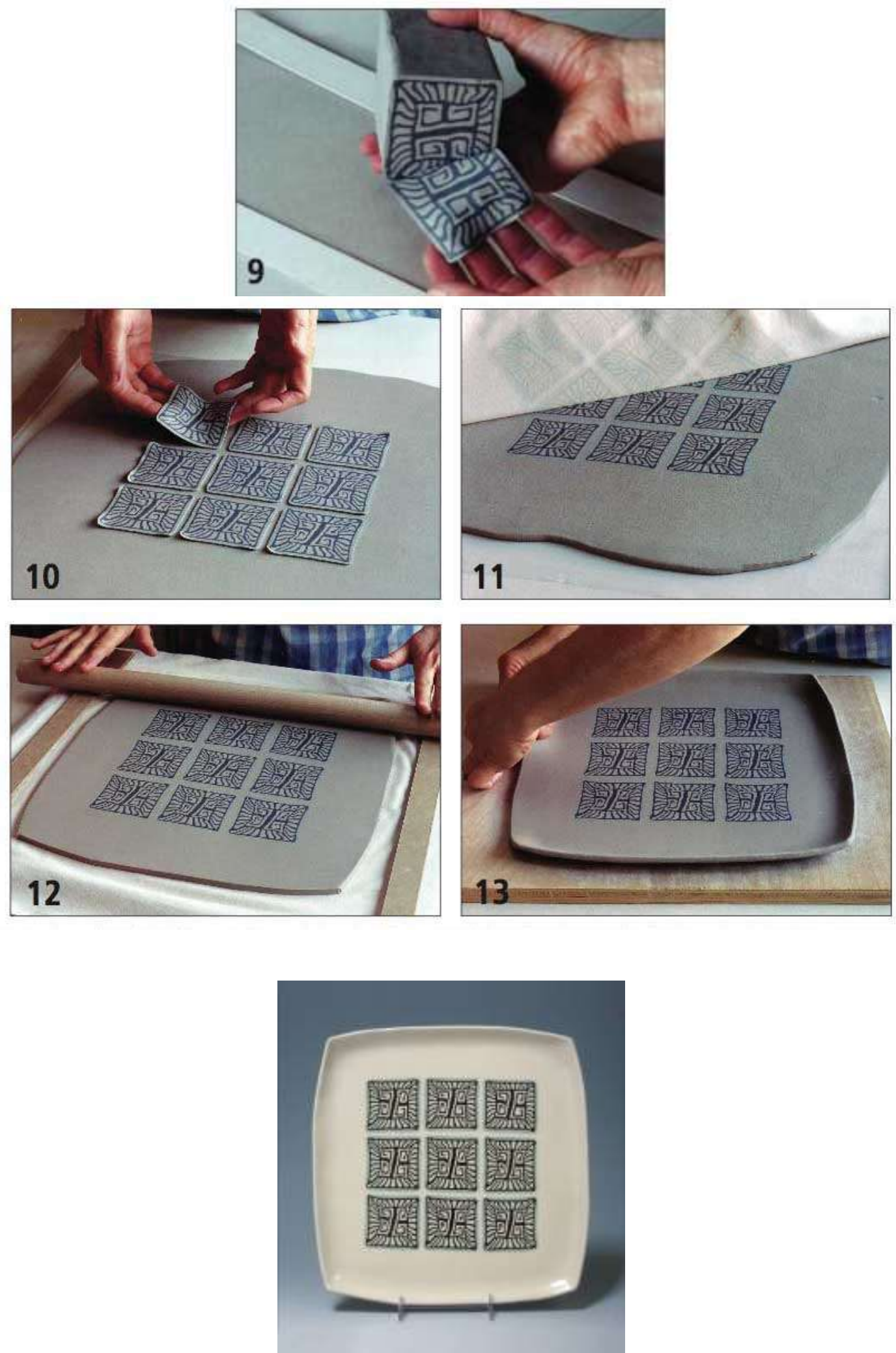

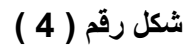

يوضح طريقة النيريكومى و كيفية تطبيقها

(1)http://ceramicartsdaily.org/ceramic-supplies/ceramic-colorants-ceramic-supplies-2/creating-neriage-blocksdecorating-with-colored-clay-patterns/ 


\section{الفرق بين النيرياج Neriage و النيريكومى Nerikomi :-}

"نيرى" Neri هى كلمة تعنى "الخلط"، " أج " Age هى كلمة تعنى " سحب ما يصل ". مما يشير أن النيرياج تشكل بعجلة الخز اف مع الطين الملون. أما "كومى" Komi هى كلمة يعنى " للضغط على " تعنى أنها تشكل بالضغط فى قالب.

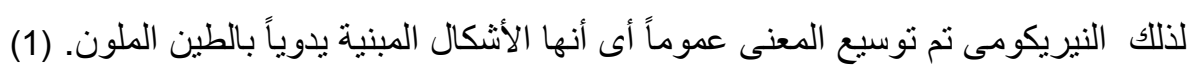

4- الميلفيورى Millefiori

مصطلح مرتبط بعملية التصميم عند قدماء الرومـان، أو ربمـا تقنيات أعمال الزجاج المصرية، وأيضـاً تدعى الفسيفسـاء الزجاجى، كما أطلق عليه " الألف زهرة Thousand Flower ". ربمـا يرجع ذلك إلى تكر ار الوحدات الناتجة من

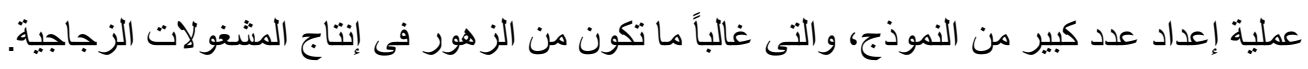

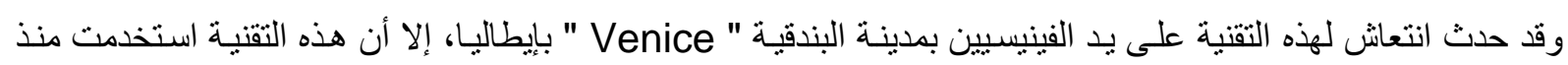

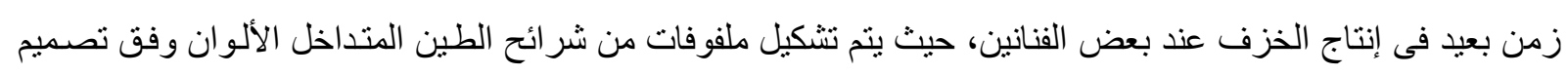
مسبق لإعداد نموذج ميلفيورى، ويظهر النموذج الملون عند عمل مقطع عرضى ويتم دمـج الوحدات الطينيـة الملونـة الناتجة مع بعضها البعض داخل قالب جصى أو باتباع البناء المباشر باليد.

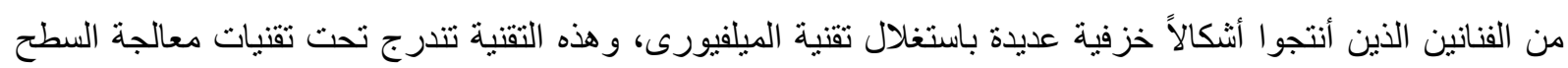

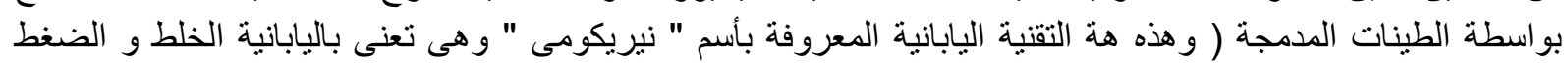

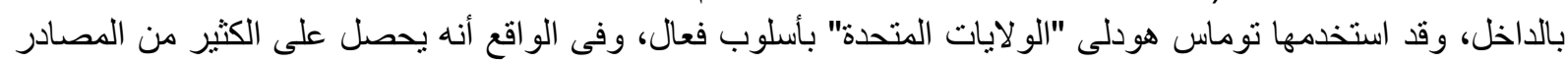

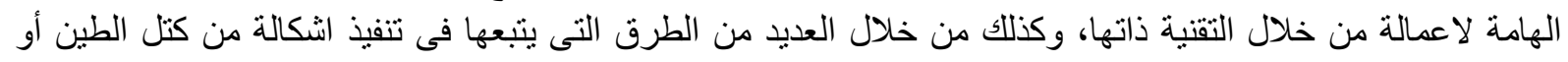

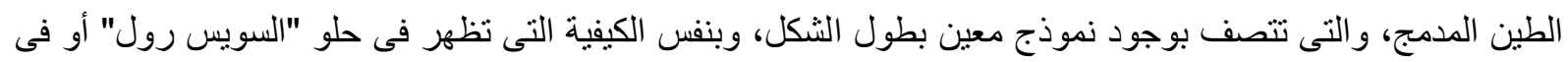

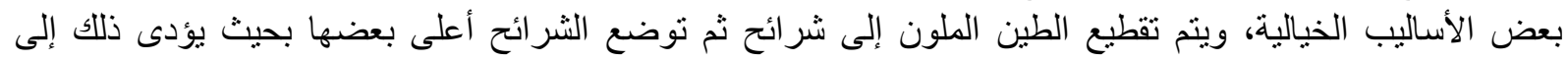

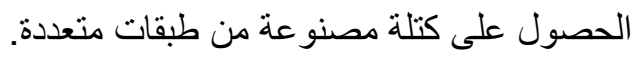

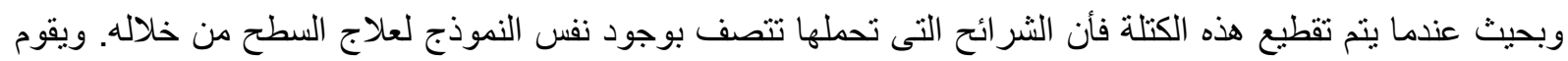

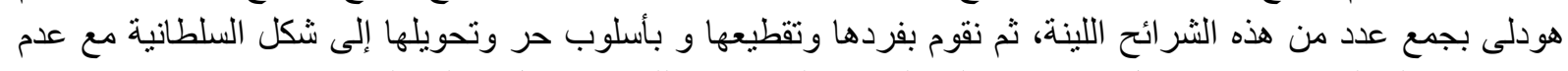

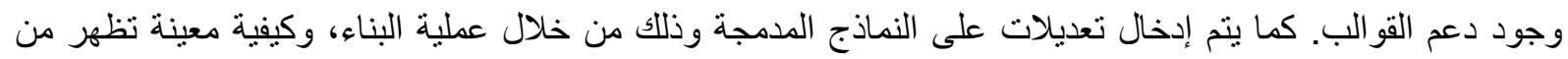

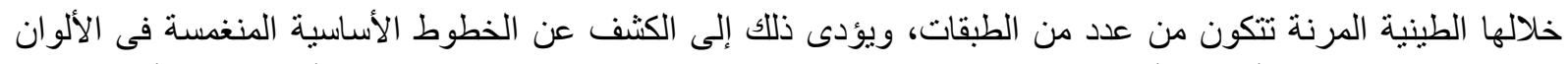

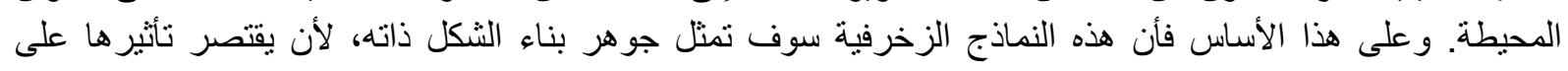

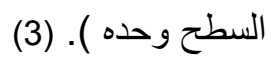

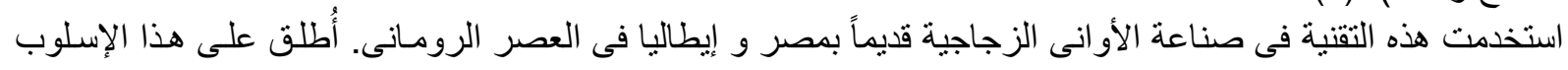

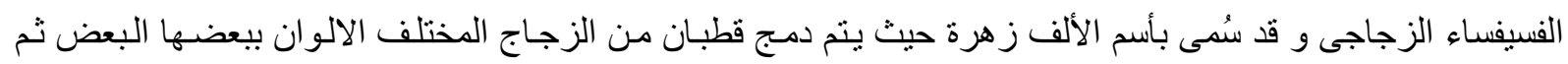

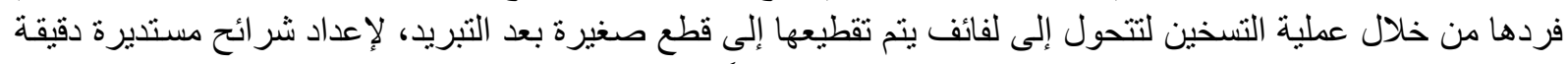

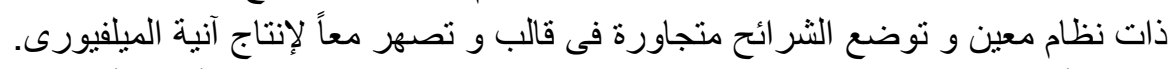

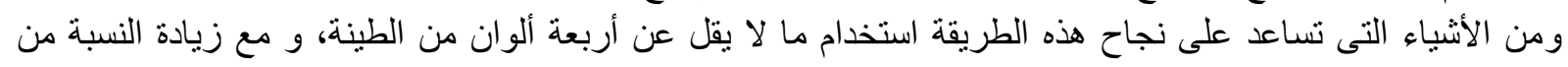
مسحوف الطين المحروق (Grog) تصل إلى 0 ( ) و يؤدى ذلك إلى خفض معدل الإنكماث حتى لا تتشقق و تنفصل

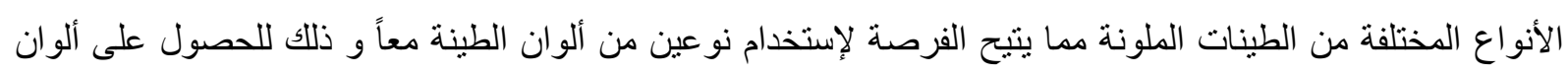

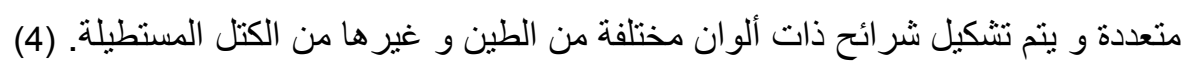

(1)https://www.facebook.com/groups/1538933016371340/permalink/1777784922486147/

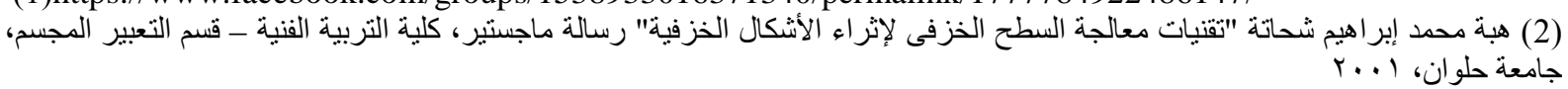

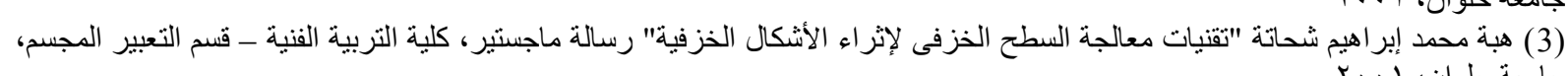

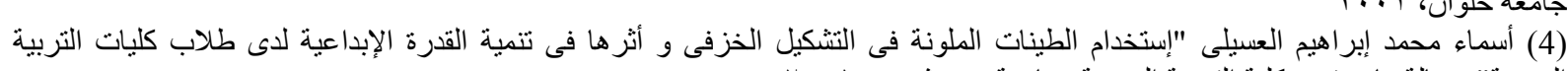

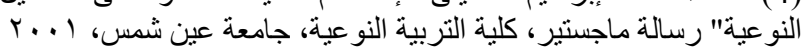


ومن بين الأمنلة العديدة النى قام بإنتاجها الفنان نوماس هودلى الثكلان ( 5 ، 6 )، شكل رقم ( 5 ) سلطانية وبر تلومى، و هى مشكله بتقنية الميلفيورى من خلال الطين الملون من البورسلين المدمج، حيث تم تشكيلها من خلال الرقائق المتجاورة و المتلاصقة فى قالب جبس. تم بعد ذلك بسط الثكل وتثكيله يدوياً حتى يمكن الكثف عن الطبيعة الناعمة

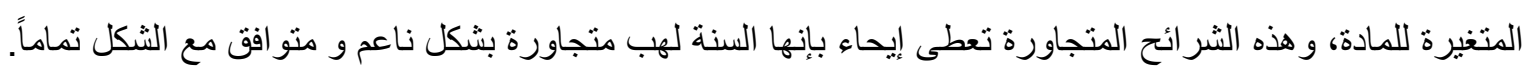
أما عن المثال رقم ( 6 ) فهو منفذ بنفس التقنية وقد قام بإستخدام العنصر الخطى بشكل ناعم و انسيابى فأدخل مع العنصر

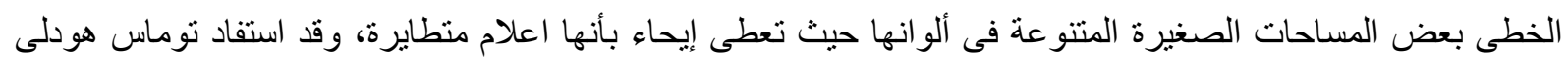

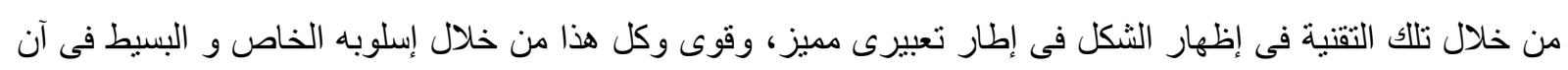
واحد.

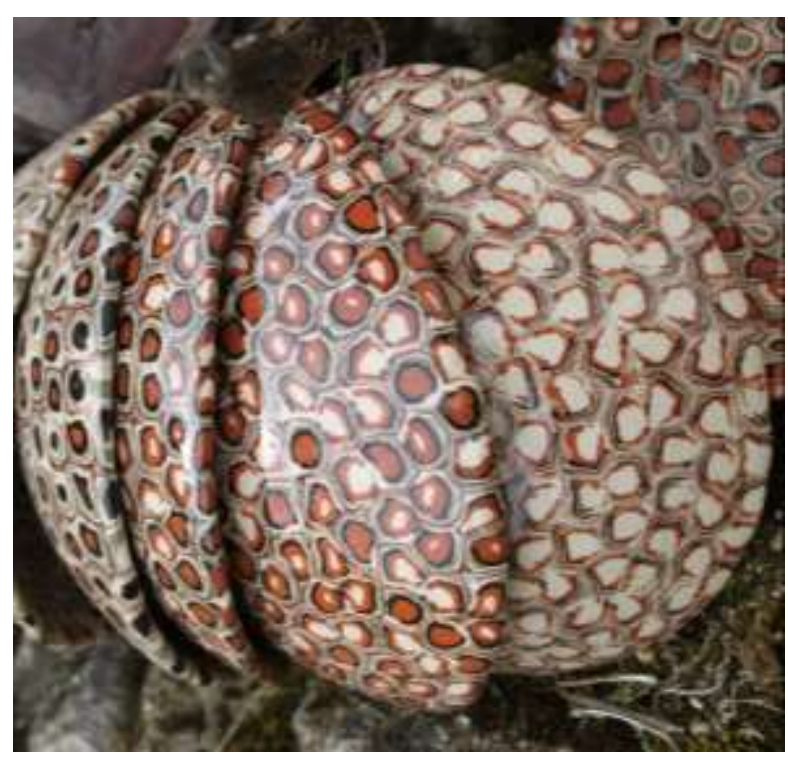

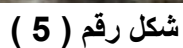

يوضح شرائح متجاورة تعطى إيحاء بشكل الزهر تم تثكيلها من خلال الرقائق المتجاورة والمتلاصقة فى قالب جبس

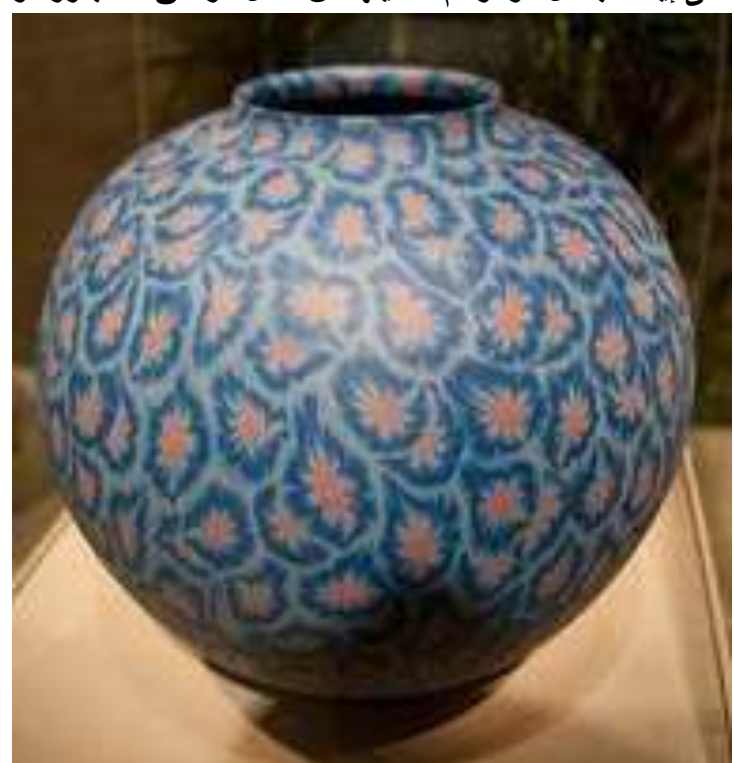

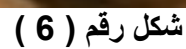

يوضح مساحات صغيرة متنوعة فى ألو انها حيث تعطى إيحاء بأنها أعلام منطايرة تم تثكيلها من خلال الرقائق المتجاورة والمتلاصقة فى قالب جبس

(1)https://www.pinterest.com/pin/257690409904690910/?lp=true

(2) https://www.pinterest.com/pin/152137293643590358/?lp=true 


\section{الشروط الواجب مراعتها عند التشكيل بتقتية الطين المدمج:}

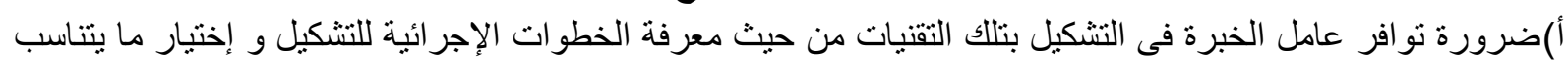
منها لتنفيذ الفكرة أو التصميم.

ب)|ختبار الخامات المناسبة وإعداد خلطات طينية بيضاء منها. ج) إضافة الملونات من الأكاسيد والأصباغ بنسب مختلفة للحصول على مجمو عات من الطين المتباين و المختلف الألوان. د) التأكد من دمج الطينات الملونة المختلفة أثناء عملية التشكيل ويستحسن إستخدام محلول طين كمادة لحام بين كل من شريحة ملونة و آخرى. واستخدام الأدوات أحسن استخدام. ه)مر اعاة عملية التجفيف فيجب أن تتم ببطئ شديد وفى جو مناسب فإن هذه المرحلة من أهم المراحل على الإطلاق حتى لا يتعرض العمل الخزفى للتشقق أو الإنهيار. و)الحرق البطئ حتى الوصول إلى الدرجة العالية المناسبة يجب أن تتم هذه العملية على مراحل متدرجة من الحرارة، وكذللك فان بعض الأشكال ربما تحتاج إلى التدعيم أثناء الحريق حتى تساعدها فى الاحتفاظ بهيئتها دون نشويه، وخاصة

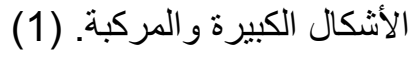

النتائج و التوصيات

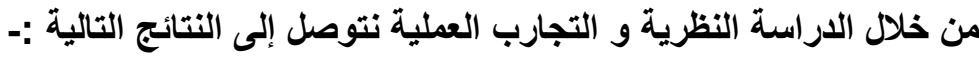

•تستخدام أكثر من تقنية بشرط توافر النظم التشكيلية و تحقيق القيم الجمالية و التعبيرية و الوظيفية فى تشكيل الخزف. •تطور استخدام الطينات الملونة بشكل أدى إلى تغير مفهوم اللون فى الثكل الخزفى حيث أصبحت هى الخامة التشكيلية فى مرحلة البناءو العنصر الزخرفى اللونى فى نفس الوقت. •استخدام الطينات الملونة يثرى القدرة الإبداعية لدى الباحث فقد ابتكر أنكالا غير تقليدية تبرز الجامة المستخدمة. •بتنوع معالجات الأسطح يمكن إيجاد العديد من الحلول الزخرفية الجمالية للتصميم الواحد. •بالاستعانة ببعض التقنيات التقليدية يمكن إيجاد حس جديد للتقنية و ذلك بإستخدام التكنولوجيا الحديثة. •يمكن أضافة تأثير ات جمالية متنو عة باستخدام التقنيات المستحدثة. •ضعف استخدام اساليب التقنيات المستحدثة ف مصر. •يرتبط هذا البحث بقسم الخزف إرتباطاً جذرياً بإعباره يهنم بمعالجة الأسطح الخزفية باستخدام الطينات الملونة. التوصيات • التوسع فى استخدام الطينات الملونة فى مصر . •الإهتمام بدراسات الطينات الملونة و التقنيات و الأساليب الحديثة لمعالجة الأسطح الخزفية و ربطها بأساليب التشكيل

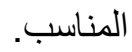
•هناك العديد من طرق معالجة الأسطح يمكن أن تثرى منتجات خزف الأستوديو و تفتح لها مجالاً جديداً فى السوق

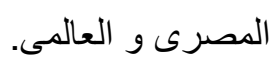
•يُتيح إستخدام الطينات الملونة و التقنيات الحديثة فى معالجات الأسطح فتح مجالاً جديداً لمنتجات الخزف. •أهمية متابعة التطورات السريعة التى تطر أ على مجال معالجة الأسطح الخزفية.

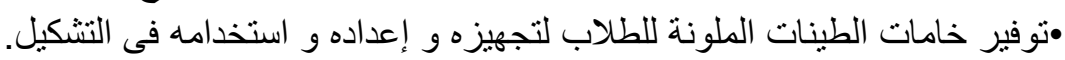
(1) و ائل فاروق إبر اهيم "در اسة تجربية لمعالجة سطح الإناء الخرفى من خلال تقنية النيرياج" رسالة ماجستير، كلية التربية الفنية، جامعة حلوان، 
1. https://www.britannica.com/art/agateware

2. شحاتة، هبة محمد إبر اهيم "تقنيات معالجة السطح الخزفى لإثراء الأشكال الخزفية" رسالة ماجستير، كلية

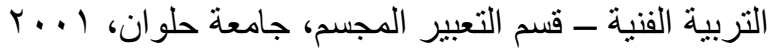

3. العسيلى، أسماء محمد إبر اهيم "إستخدم الطينات الملونة فى التشكيل الخزفى و أثرها فى تندية القدرة الإبداعبة للدى طلاب كليات التربية النوعية" رسالة ماجستير ، كلية التربية النوعية، جامعة عين شمس، ل ...

4. http://www.dailyartmuse.com/2007/01/02/neriage-nerikomi/

5. إبر اهيم، وائل فاروق "در/سة تجربية لمعالجة سطح الإناء الخرفى من خلال تقنية النبرياج" رسالة ماجستير،

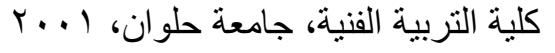

6. http://ceramicartsdaily.org/ceramic-supplies/ceramic-colorants-ceramic-supplies2/creating-neriage-blocks-decorating-with-colored-clay-patterns/

7. https://www.facebook.com/groups/1538933016371340/permalink/1777784922486147

8. https://www.pinterest.com/pin/290130400976880900/?lp=true

9. http://www.chipstone.org/article.php/78/Ceramics-in-America-2003/Swirls-andWhirls:-English-Agateware-Technology

10. https://www.pinterest.co.uk/pin/557883472586393802/?1p=true

11. https://www.pinterest.com/pin/152137293643590358/?lp=true

12. https://www.pinterest.com/pin/257690409904690910/?1p=true 